\title{
Book Review: Approaches to qualitative research in mathematics education: Examples of methodology and methods, edited by Angelika Bikner-Ahsbahs, Christine Knipping, \& Norma Presmeg. (2015) Dordrecht: Springer. doi:10.1007/978-94-017-9181-6. eBook: ISBN 978- 94-017-9181-6, €83.29. Hardcover ISBN 978-94-017-9180-9 €99.99. Softcover ISBN 978-94-024-0688-7 €99.99. 592 pages
}

Keith Jones ${ }^{1}$ \& Chronoula Voutsina

\section{Introduction}

This book, Approaches to Qualitative Research in Mathematics Education: Examples of Methodology and Methods, edited by Angelika Bikner-Ahsbahs, Christine Knipping, and Norma Presmeg, is a timely and valuable addition to the research literature in mathematics education. By providing what the editors say are "detailed descriptions of how qualitative methodologies are substantiated in a specific project, how they are implemented to investigate a research question, and how they are used to capture the research objects" (p. v), the book offers a range of insight and detail that goes beyond what is normally possible within individual articles in mathematics education research journals. The book complements other efforts to capture the many advances in the mathematics education research field over recent years, such as the series of Topical Surveys published to mark the 13th International Congress on Mathematical Education (ICME-13) and the second PME research handbook that details and analyses the research presented at PME conferences between 2005 and 2015 (Gutiérrez, Leder, \& Boero, 2016).

As already noted, the book is timely, given the current propensity of some research funding agencies and initiatives to prioritise quantitative approaches to research in education and the

Keith Jones

d.k.jones@soton.ac.uk

\footnotetext{
${ }^{1}$ Southampton Education School, University of Southampton, University Road, Southampton SO17 1BJ,
} UK 
wider social sciences. Indeed, the book is a confirmation of the efforts across the field of mathematics education research to provide a rigorous basis for qualitative research. The book is a valuable contribution to the research field in that, as Schoenfeld $(2016$, p. 514) says in his contribution to a volume of the Review of Research in Education marking 100 years of education research, the contemporary situation with regard to research methods is "dynamic", with "new theoretical orientations [that] bring with them a plethora of methods". This plethora of methods provides challenges for the field of mathematics education research and special challenges for new and beginning researchers. This book helps to meet such challenges.

For this review, we begin by examining the range of research approaches detailed in the book before going on to explore some of the wider issues prompted by our reading of the book. In trying to capture the essential detail of each part of the book, we have striven to maintain a balance of coverage. After much deliberation, we decided that extending the consideration given to some longer chapters or sections of the book would compromise this balance.

\section{The book}

Across 18 chapters written by more than 30 prominent researchers, many highly experienced and some less so, together with a Preface and a final Looking Back chapter by the book's three editors, the book provides a detailed compendium of approaches to qualitative research in mathematics education that, in some cases, have been developed over a number of years. Indeed, the book builds on two issues of ZDM from 2003 that focused on qualitative methods. The book does this by "bringing additional depth and variety, and including the close relationship between theory and methodology" (p. v).

The book is divided into 12 parts, with 11 of these each detailing a specific approach to qualitative research; the final part being a closing chapter by the book editors in which they "reflect on the interconnection between methodology and research practice" (p. 533). Each of the 11 parts encompasses both "a description of the theoretical and methodological underpinnings of the research approach and a concrete research example of how the approach is used in practice" (p. vi; emphasis added). In some, the underpinnings and the example appear as two separate chapters (sometimes with different authors) while in others the underpinnings and the example are integrated into a single chapter. The one exception is the part entitled "Design Research as a Research Methodology" which has three chapters; we discuss this further below.

As the editors explain in Part XII, the initial intention was that all the other 11 parts of the book were to consist of two separate chapters as this would "allow the reader to use the book as an actual guide for the selection of an appropriate methodology, based on both theoretical depth and practical implications" (p. 533). In developing the book, the team of editors and authors recognised that some methodologies were "much more tightly linked to research practice" (p. 533) so that having separate chapters (as described above) was not the most appropriate arrangement in such cases. This illustrates how the link between methodology and theory may, as the book's editors say, be of "varying degrees" (p. 534).

Neither in their preface, nor in their final Looking Back section, do the editors of the book give an indication of how the order of the 11 parts was decided. In this review, rather than examining each part in the order that it appears in the book, we explore the various sections from the perspective of how the link between methodology and theory appears to be of "varying degrees" (p. 534). 


\subsection{Methodology and theory intertwined}

We begin with examining parts IV and V of the book where, to us, methodology and theory appear entirely intertwined.

Part IV of the book comprises a single chapter, The Question of Method in a Vygotskian Semiotic Approach, in which Luis Radford and Cristina Sabena integrate the theoretical and methodological underpinnings of a Vygotskian semiotic approach with a concrete research example. This chapter gives serious consideration to the issue of what the authors refer to as method by building the case that "it would be a mistake to think that methods precede the inquiry or research that they are supposed to support" (p. 159). Radford and Sabena view their goal as being to account for "the manner in which the whole range of semiotic resources are used by teachers and students in the course of the social processes of objectification through which students become aware of the cultural logic and meanings of thinking and doing mathematically" (p. 167). In relation to this, two methodological constructs are utilised: the semiotic node and the semiotic bundle. The example they analyse is from a set of lessons with grade 9 students that concern pattern generalisation as a way to build algebraic thinking (the lessons being designed by the researchers in collaboration with the teacher). Through detailing their fine-grained semiotic analyses, Radford and Sabena illustrate how they use the notion of semiotic node as "a synchronic tool to focus on the manner in which students endow with meaning their actions in coming to discern mathematical relationships and structures in their work", and the notion of semiotic bundle as "a diachronic tool to follow the evolution of signs" interrelationships in the course of the activity" (p. 179). The attention to method, combined with their fine-grained analyses, gives detailed insight into their approach to their research.

Part $V$ of the book is also a single chapter, The Nested Epistemic Actions Model for Abstraction in Context: Theory as Methodological Tool and Methodological Tool as Theory. Here, the team of Tommy Dreyfus, Rina Hershkowitz, and Baruch Schwarz focus on understanding how students construct abstract mathematical knowledge. In summarising their theoretical framework of abstraction in context (AiC) that they use for studying "students' processes of constructing abstract mathematical knowledge as it occurs in a context that includes specific mathematical, curricular and social components as well as a particular learning environment" (p. 185), they show how a central component of AiC is what they call a theoretical-methodological model, according to which the emergence of a new construct is described and analysed. This theoretical-methodological model entails "three observable epistemic actions" (p. 188) that they define as recognising (R), building with (B), and constructing (C), and refer to as the $\mathrm{RBC}$ model (subsequently the $\mathrm{RBC}+\mathrm{C}$ model, with a second $\mathrm{C}$ to underline the important role of knowledge consolidation). There is, they say, a twofold goal of an analysis using this $\mathrm{RBC} / \mathrm{RBC}+\mathrm{C}$ model: first, to "unveil the processes by which the students' new constructs emerge as a vertical reorganization of previous constructs in the current context" and, second, to "contribute to the refinement of AiC through the unfolding of the processes that occurred during the episodes" (p. 194). The example of analysis that they unveil involved a ten-lesson probability unit that they videoed being taught to five grade 8 classes across different schools. In an a priori analysis, they show how they identified four basic probability concepts as the main knowledge elements within the learning design that were expected to be constructed by the students during the lessons: simple event, compound event, sample space, and probability value. Focusing on three students, their detailed analysis traces the epistemic actions of recognising, constructing, building with, and consolidating in students' meaning-making activity in mathematics, and shows how each student constructed their 
individual knowledge in their own way and time. The authors contend that, throughout the various stages of its development, "the $\mathrm{RBC}+\mathrm{C}$ model has been validated, both as a theoretical framework and as a methodological tool, in various social settings and learning environments" (p. 213).

\subsection{Methodology intimately informed by theory}

In Part VI of the book, ideas of methodology are intimately informed by theory. Here there are two chapters by the same pair of authors, Ivy Kidron and Angelika Bikner-Ahsbahs. The two chapters have as their focus the networking of theories as an approach to qualitative research in mathematics education.

In the first of the two chapters, Advancing Research by Means of the Networking of Theories, Kidron and Bikner-Ahsbahs explain how the networking of theories "informs methodological principles of how different theories can be used and what kind of benefit can be obtained by the use of different theories" (p. 221). They introduce the term cross-methodology for "special techniques and methods employed to enhance and enable networking, such as crossexperimentation between research teams and cross-case analysis in which material gained in one theory team is experimented with or analyzed by another theoretical view" (p. 225). In doing so, they illustrate cases of how the networking of theories can have different goals, including (a) the complementary insights that can result from analysing given data with different theories, (b) developing deeper understanding of an empirical situation by means of connecting two or more different theoretical perspectives, and (c) building an enlarged framework in relation to some new domain of research. The authors use a diversity of theories to explore the insights offered by each theory while, at the same time, revealing the limits of such an effort.

In the follow-up chapter, A Cross-Methodology for the Networking of Theories: The General Epistemic Need (GEN) as a New Concept at the Boundary of Two Theories, Bikner-Ahsbahs and Kidron detail how they employed the "networking" of two epistemic actions models (i.e., where epistemic actions are "actions which lead to constructing mathematical knowledge" $p$. 236) to yield "a new concept at the boundary of the two theoretical approaches" (p. 233). The two theories utilised were AiC (the focus of Part V of the book, see above) and the theory of interest-dense situation (IDS) (where the latter focuses on "the construction of knowledge as an epistemic process in social interaction which emerges when different people together solve a mathematics task" p. 235). The rationale that underpins the networking of the two different theoretical perspectives is that they "both use similar epistemic actions models for analyzing processes of constructing knowledge" (p. 234). In the project, three mathematical tasks were designed for pairs of students in grade 10 to investigate the processes that led to the construction of mathematical knowledge. Through a detailed analysis, Bikner-Ahsbahs and Kidron show, on the one hand, how the notion of a general epistemic need (GEN) (described as "the students' need to proceed in an epistemic process looking for ideas to solve a task" p. 237) emerged when the AiC approach showed the need for a new construct; and how, on the other hand, the IDS approach suggested that a more general epistemic need might be driving the epistemic process. In this way, the cross-methodology (a series of five cross-over stages guiding the research) led to "a new kind of concept [the GEN] of which both theories could make sense" (p. 248). 


\subsection{Methodology alongside a theoretical framework}

In Parts II and VII of the book, there were examples of methodology alongside a theoretical framework.

In the first chapter of Part II, Methods for Reconstructing Processes of Argumentation and Participation in Primary Mathematics Classroom Interaction, Götz Krummheuer presents two methods of analysis based on the theoretical viewpoint that mathematics learning depends on the students' participation in collective argumentation. The contention is that the two different approaches to micro-analysis can allow researchers to elucidate the local social conditions of learning at the interactional level. The research example that follows, Reconstructing Argumentation Structures: A Perspective on Proving Processes in Secondary Mathematics Classroom Interactions, is by Christine Knipping and David Reid. This example utilises "a variant" (p. 75) of the approach outlined by Krummheuer. The need for a variant of approach is that while there is "considerable methodological overlap between the methods" (p. 76), there are "differing research contexts and interests" (p. 76). In this case, Knipping and Reid are "more interested in learning argumentation than in argumentative learning" (p. 76; emphasis in the original). Whereas Krummheuer's approach allows for the very close examination of argumentation in a single classroom, and the relating of argumentation to participation, the approach of Knipping and Reid aims for an overall picture of the argumentation thus permitting comparisons between classrooms. Such detail is invaluable for those interested in analysing argumentation in mathematics classrooms.

Part VII is a single chapter, Understanding Learning across Lessons in Classroom Communities: A Multi-leveled Analytic Approach, by Geoffrey Saxe, Kenton de Kirby, Marie Le, Yasmin Sitabkhan, and Bona Kang. In this, the authors “draw on Saxe's framework on the cultural development of mathematical ideas [by] adapting it to an analysis of classrooms which [are treated] as microcultural communities engaged with shifting collective problems" (p. 255) (i.e., shifting over space and time). Using the term common ground to index their focus on a "taken-as-shared public discourse", they "present a conceptual framework that treats classroom activity at two levels of analysis, collective and individual" (p. 253). The authors take common ground at the collective level to be "the production of taken-as-shared norms that support the coordinated actions of participants in joint activity" (such as turn-taking in classroom discussion as well as norms for mathematical argumentation and justification), and common ground at the individual level to be "generated as individuals produce and interpret displays of mathematical thinking, making use of representational forms (linguistic, graphical, gestural) to serve communicative and problem solving functions" (pp. 255-256).

In the first part of their empirical analysis, the authors used design research (see Part XI, described below) to develop a lesson sequence for the upper elementary grades on the topic of integers and fractions that would "engage a classroom community with a progressive elaboration of a common ground of talk and action" (p. 270). For their analysis, they chose to focus on the references made to definitions by teacher and students. The detailed analysis entails a multilevel approach of microgenetic analysis (at the level of representations), sociogenetic analysis (attending to the way microgenetic constructions are distributed over individuals), and ontogenetic analysis (as individuals adapt forms to serve communicative and problem solving functions). The analysis revealed two socio-mathematical norms: the Buse of mathematical definitions when explaining thinking or justifying reasoning $\wedge$, and Bthe way definitions were used in public displays ${ }^{\wedge}$ (p. 297). The authors regard their approach as a useful starting point for “opening up new conceptual and empirical territory in classroom research" (p. 316). 


\subsection{Methodology and theory building}

In several parts of the book, the attention is on methodology and theory building.

In Part I of the book, there are two chapters that address grounded theory. In the first of these, Grounded Theory Methods, Anne Teppo provides an overview of how the approach and associated research techniques of data coding and analysis cycles within grounded theory have evolved and been developed by different authors. The structure of the chapter is interesting in that, as it moves from an account of methods and techniques to a discussion on methodological paradigms, it reflects the way the writings about grounded theory by different authors have also evolved through the years. In the research example, To See the Wood for the Trees: The Development of Theory from Empirical Interview Data Using Grounded Theory, Maike Vollstedt tackles the difficult task of illustrating the complex analytical process by zooming in to the specifics of code emergence and zooming out to the identification and extraction of key ideas that can be connected with different kinds of personal meaning. Ultimately, she was able to construct a theoretical framework of personal meaning, the focus of her research.

Part III, Ideal Type Construction, continues with the pattern of two chapters, this time both by Angelika Bikner-Ahsbahs. Here the focus for the first of the two chapters, Empirically Grounded Building of Ideal Types: A Methodical Principle of Constructing Theory in the Interpretative Research in Mathematics Education, is how the development of ideal types (a notion from sociologist Max Weber) can be regarded as "a methodical principle which "points the way' for an empirically-based theorizing” (p. 105). As Bikner-Ahsbahs explains, developing ideal types entails beginning with, say, classroom observation, and developing conceptually coherent (hence, ideal) notions as a way to ascertain similarities and differences across the specific cases. As such, theory development involves "empirically-based ideal type constructions" such that "these ideal types now present the conceptual base for a further theory development" (p. 131). In the example chapter that follows, How Ideal Type Construction Can Be Achieved: An Example, the development of an analysis of ideal types is shown in detail, focusing in interest-dense situations (see also chapter 10). These analyses illustrate how "the ideal types are used to deepen understanding of the empirical cases" (p. 153), even though, as Bikner-Ahsbahs states, ideal types are theoretical constructs rather than an exact reflection of reality.

Part XI, the final section that details an approach to qualitative research, is devoted to design research. Here, in contrast to the pattern of earlier parts, there are "three alternate approaches to design-based research" (p. vi). In the first of the chapters, An Introduction to Design-Based Research with an Example From Statistics Education, Arthur Bakker and Dolly van Eerde provide an overview of educational design-based research (DBR), where "the design of educational materials ... is a crucial part of the research" (p. 430). They say that the purpose of DBR is to "develop theories about learning and the means that are designed to support that learning" (p. 437) and characterise DBR as being interventionist and cyclic in nature with an iterative process of three phases: "preparation and design, teaching experiment, and retrospective analysis" (p. 438). Their example is an account of a project aimed at "an empirically-grounded instruction theory for early statistics education with new computer tools for the age group from 11 to 14" (p. 446) that illustrates in detail the steps involved in conducting DBR. In the middle chapter of the three, Perspectives on Design Research: The Case of Didactical Engineering, Michèle Artigue describes the development of Didactical Engineering (DE) as "a research and development methodology based on classroom realizations in form of sequences of lessons, informed by theory and putting to the test theoretical ideas" (p. 469). DE 
is undertaken as a series of phases: preliminary analyses, conception and a priori analysis, realisation, observation and data collection, and a posteriori analysis and validation. Artigue illustrates the approach through two examples: (a) a set of 65 lessons on extending whole numbers to rational and decimal numbers taught to a 4th grade class, and (b) a set of lessons introducing high school students very early to functional objects fundamental in calculus and analysis through the introduction of the derivative in terms of local linear approximation. The third chapter in the section, Educational Design Research to Support System-Wide Instructional Improvement, by Erin Henrick, Paul Cobb, and Kara Jackson, describes the use of educational design research as a "methodology... to support large-scale instructional improvement in mathematics" (p. 497) and as a way "to develop an initial, tentative, and eminently revisable theory of action" (p. 502) that leads to further iterations of the theory of action. Their approach is illustrated by the example of the project Designing Learning Organizations for Instructional Improvement in Mathematics (known as MIST), which "investigated how school- and systemlevel supports and accountability relations impacted the quality of mathematics instruction" (p. 498) in schools for students aged 12-14.

\subsection{Methodological issues}

A further tranche of the book deals with important methodological issues when conducting research.

The title for the single 12th chapter that comprises Part VIII is The Combination of Qualitative and Quantitative Research Methods in Mathematics Education: A "Mixed Methods" Study on the Development of the Professional Knowledge of Teachers. Here, Udo Kelle and Nils Buchholtz consider the different possibilities that a mixed methods approach offers for "a mutual validation of both qualitative and quantitative findings" (p. 321). In this they make the point that

it is never sufficient simply to piece together different types of data and analysis methods. On the contrary, researchers must make sure that the different data and methods used are related to an overarching conceptual framework, so that the mixing of methods does not break the research question, research topics and theoretical base of the project into unrelated parts. (p. 324)

To illustrate mixed methods possibilities in research in mathematics education, Kelle and Buchholtz present the example of a project designed to evaluate a new pre-service teacher education programme. In their analysis, they show how qualitative and quantitative data were combined in order to "gain a deeper understanding of the development of [teacher] professional competence and the different results regarding achievements [on the different teacher education programmes]" (p. 350). The chapter concludes with an overview of the different functions of mixed methods designs.

In the first of the two chapters in Part IX, Qualitative Content Analysis: Theoretical Background and Procedures, Philipp Mayring provides the theoretical and methodological underpinnings of qualitative content analysis. The chapter outlines "a bundle of text analysis procedures integrating qualitative and quantitative steps of analysis", which, in the words of the author, makes it "an approach of mixed methods" (p. 365). The approach entails combining a qualitative-interpretative step in the analysis (which uses hermeneutical logic in assigning categories to text passages) with a quantitative analysis of frequencies of those categories (when 
the same categories are coded in several text passages). He outlines three kinds of analytical techniques which may be linked with two kinds of category formation, described more fully below. In the follow-up chapter, A Study on Professional Competence of Future Teacher Students as an Example of a Study Using Qualitative Content Analysis, Björn Schwarz reports an analysis of "structures within the professional competence of future teachers [of mathematics]" (p. 384). The first stage of the analysis entailed using deductive category application. The second stage focused on inductive coding, while the third stage was deductive coding in which "deductively defined codes can be set into relation with other deductively defined codes and inductively defined codes can be set into relation with other inductively defined codes as well as deductively defined codes can be set into relation with inductively defined codes" (p. 393). The finely-detailed analysis exemplifies "how future mathematics teachers' answers to open questions are coded according to both deductively and inductively developed coding manuals to address the research question related to structures between areas of the future teachers' professional competence" (p. 397).

In Part X, Triangulation and Cultural Studies, the single chapter by Ida Mok and David Clarke, The Contemporary Importance of Triangulation in a Post-Positivist World: Examples from the Learner's Perspective Study, argues that "conceptions of triangulation must be broadened if it is to be relevant to a community increasingly committed to interpretivist and critical methodologies" (p. 403). This is particularly the case, the authors maintain, in crosscultural comparative research. Here, while certain research approaches (such as mixed methods) may afford triangulation of data types, Mok and Clarke suggest that the significance of triangulation lies in "its function as a particular form of design logic: generating evidence through the strategic juxtaposition of design elements". They continue that the effects of triangulation of informants, of research techniques, of cultural settings, and of researchers' theoretical frameworks "lie in the inevitable generation of interpretive accounts that must logically be viewed as complementary" (p. 404). To exemplify their research approach, Mok and Clarke provide a finely detailed analysis from a component of the Learner's Perspective Study, a project conducted in several different countries designed to examine the practices of 8th grade mathematics classrooms. In this analysis, a multiplicity of data types is shown to contribute to "a complex but interconnected account of any given situation" (p. 422). The use of multiple informants (both as participants and also as retrospective commentators) foregrounds "the separate legitimacy of each participant's interpretation of events, rather than their capacity to be mutually validating, and highlights the need to document the intentions, actions and interpretations of each" (p. 422). The use of different theories provides "alternative analytical perspectives" that "offer a less partial portrayal of the situation of interest" (p. 422), while cultural triangulation "offers the opportunity for the rich portrayal of activities or phenomena having familiar form but varied function" (p. 422). Mok and Clarke conclude that triangulation "can serve the aspiration to accommodate and characterise complexity rather than conceal or minimise it" (p. 423).

\section{Discussion and wider issues}

The book succeeds amply in its aim of documenting a range of qualitative research approaches that have been developed in mathematics education over recent decades. The choice of approaches to detail is informed, but also somewhat eclectic. The selection is, for example, quite far removed from what might be found in a handbook of qualitative research: there is no specific 
mention in the subject index of ethnography, for instance, nor case study. In some ways, this choice is without doubt a strength of the book; it not only captures some of the richness of progress in qualitative approaches to research but is also an unrivalled source of detail on those approaches. A drawback might seem to be that there is no room in the book (or perhaps no intention) to include advice on how to choose between the different approaches. Rather, as the editors state in the Preface, the basic structure of the theoretical and methodological underpinnings of an approach that is then illustrated by concrete research examples is intended to illuminate the conduct of each approach. This unrivalled detail is of course extremely helpful - yet each approach is so detailed and intricate that a novice researcher may at first feel a little overwhelmed.

Given that each approach is presented by adherents, and presented very ably, another issue is that there is little room in the book for critique of the approaches that are covered. Nor is there any explicit attention to research ethics (another term absent from the book index). The authors of the various parts do pay close attention to how to conduct their approaches to qualitative research in the best possible way; the parts of the book on grounded theory and on design research, for example, as well as abstraction in context $(\mathrm{AiC})$ and a semiotic approach, among many others, each provide valuable guidance on the nuances of the respective approaches. However, there is less attention across the book to where an approach may not be appropriate. The sensible device of focusing the research example to be analysed on a successful instance can tend to limit attention to where the approach may have been less than successful. That said, there is advice on sources of error. For example, Kelle and Buchholtz (pp. 354-355) address possible sources of error in using mixed methods, pointing out that methodological 'rules' should be taken as general guidelines whose significance varies according to context. It has to be said, of course, that no single book can hope to do everything. Even at 575 pages, the book cannot capture all the developments in qualitative research approaches in mathematics education research.

Schoenfeld (2007) observed that:

...all empirical research is concerned with and deeply grounded in (at times tacit but nevertheless strong) theoretical assumptions. Even the simplest observations or data gathering are conducted under the umbrella of either implicit or explicit theoretical assumptions, which shape the interpretations of the information that has been gathered. Failure to recognize this fact and to act appropriately on it can render research worthless or misleading. (p. 70)

This book richly illustrates that the link between methodology and theory is one of "varying degrees" (p. 534). The book also can be seen to support efforts to tackle what Burton (2002) identifies as a serious issue, namely that:

....in the majority of articles in journals and books, a description is provided on 'how' the research was done but rarely is an analysis given of 'why' and, more particularly, out of all the methods that could have been used, what influenced the researcher to choose to do the research in the manner described. (p. 1)

The book captures the important distinction between 'method' (the 'how') and 'methodology' (the 'why') by facilitating the various authors in probing the underlying assumptions of their approaches. The book is to be strongly recommended. While it is not a straightforward read, the 
various sections of the book offer unmatched insight into the conduct of important research in mathematics education.

Acknowledgements We wish to express our thanks to Gail FitzSimons, the ESM Book Reviews editor, for support in conducting this book review. Any errors remain ours, of course.

\section{References}

Burton, L. (2002). Methodology and methods in mathematics education research: Where is 'the why'? In S. Goodchild \& L. English (Eds.), Researching mathematics classrooms: A critical examination of methodology (pp. 1-10). Westport: Praeger.

Gutiérrez, A., Leder, G., \& Boero, P. (Eds.). (2016). The second handbook of research on the psychology of mathematics education: The journey continues. Rotterdam: Sense.

Schoenfeld, A. H. (2007). Method. In F. K. Lester (Ed.), Second handbook of research on mathematics teaching and learning (Vol. 1, pp. 69-110). Charlotte: Information Age.

Schoenfeld, A. H. (2016). Research in mathematics education. Review of Research in Education, 40(1), 497528. 